\title{
A DEFESA DO CONSUMIDOR NAS RELAÇÕES DE E-COMMERCE PELO FOMENTO À PROTEÇÃO DOS DADOS PESSOAIS SENSÍVEIS NA SOCIEDADE DA INFORMAÇÃO
}

\author{
Cristina Anita Schumann Lereno Terzidis ${ }^{1}$ \\ Devanildo de Amorim Souza ${ }^{2}$
}

\section{Resumo:}

Este artigo procura analisar, com base na análise bibliográfica, apresentando-se através do método jurídico dogmático dedutivo, os direitos da personalidade de forma ampla, seu respaldo perante a Constituição da República Federativa do Brasil de 1988 e sua aplicabilidade perante o Código de Defesa do Consumidor, assim como na lei 13.709/18, tendendo resguardar os direitos intrínsecos ao ser humano perante as relações de consumo. Visa abordar também, o tratamento de dados pessoais e de dados pessoais sensíve is perante a legislação 13.709/18, no contexto protetivo legal.

Palavras-chave: sociedade da informação; direitos da personalidade; direitos fundamentais; ecommerce; e CDC.

\section{CONSUMER DEFENSE IN E-COMMERCE'S RELATIONS BY FOSTERING THE PROTECTION OF SENSITIVE PERSONAL DATA IN THE INFORMATION SOCIETY}

\begin{abstract}
:
This article seeks to analyze, based on bibliographical analysis, presenting itself through the dogmatic deductive legal method, the rights of the personality in a broad way, its support under the Constitution of the Federative Republic of Brazil of 1988 and its applicability under the Defense Code of the Consumer, as well as in law 13.709/18, tending to protect the intrinsic rights of the human being in consumer relations. It also aims to address the processing of personal data and sensitive personal data under legislation 13.709/18, in the protective legal context.
\end{abstract}

Keywords: information society; personality rights; fundamental rights; e-commerce; and CDC.

\footnotetext{
${ }^{1}$ Mestranda em Direito pelo Centro Universitário das Faculdades Metropolitanas Unidas - FMU/SP. Graduada em Direito da Faculdades Metropolitanas Unidas. Advogada. Lattes: http://lattes.cnpq.br/8686665865896351 Email: terzidisadv@ outlook.com. São Paulo/SP, Brasil.

${ }^{2}$ Mestrando em Direito pelo Centro Universitário das Faculdades Metropolitanas Unidas - FMU/SP. Graduado em Direito - FMU/SP. Bolsista CAPES. Advogado. Curriculum Lattes: http://lattes.cnpq.br/3461110540185889. ORCID: https://orcid.org/0000-0003-2489-1373. E-mail: devanildosouza@ outlook.com.br. Petrolina/PE, Brasil.
} 


\section{Introdução}

Desde a Antiguidade existia a concepção de direitos humanos adstrita e advinda do Cristianismo. A categoria de direitos da personalidade como conhecemos hoje é deveras recente e com isso a evolução dos consagrados direitos intrínsecos ao ser humano.

São direitos de berço, base do ser humano e que, portanto, já nascem com ele, assim como devem ser resguardados e garantidos em proteção necessária caso haja mácula de toda e qualquer ordem.

E que por estarem intrinsecamente ligados com o ser humano, não há o que dizer em classificá-los quanto a aplicabilidade ou não, inexistência ou não a determinadas categorias de pessoas, adquirentes, consumidores. Portanto, há existência e garantia deles independente à quem seja, sendo ser humano já é dotado dos referenciados direitos.

No entanto, pela crescente evolução do mundo pós-moderno, encontramo-nos diante da internet, acesso das redes, meios e plataformas para facilitar a aquisição e bens e serviços, inclusive, deduzida à situação antes pandêmica e agora meio pandêmica.

Notadamente antes da pandemia da COVID-19 tinha conosco o privilégio da escolha entre comprar ou não pela web, estar ou não conectado no mercado on-line, mas com a advinda da pandemia da COVID-19 nos mostrou que a inserção no mundo virtual não era mais uma escolha, mas sim uma necessidade, imposição esta de subsistência e da própria família.

Com essa reflexão tornou-se mais ainda um tema imperioso a nossa análise, pois hodiernamente dispomos de nossos dados, como nome completo, CPF, RG, endereço, em sites de mercado, farmácias, lojas de roupas, mas nem sempre isso ocorre de forma livre e consciente ou livre de coerção estrutural sistêmica promovida pelo aparato mercantil, pois se condiciona a prestação do serviço ou obtenção do somente se preenchendo o solicitado.

Porém, indaga-se se esses dados estão sendo protegidos por estas plataformas e se há tratamento adequado a estes já que não raras vezes são considerados dados sensíveis?

Atualmente são questionamentos comuns em meio à sociedade da informação e que prescinde necessariamente de abarcar para melhor compreendermos a essência da grandiosidade dos nossos direitos frente a necessidade que assola o mundo inteiro em meio a pandemia da COVID-19, mas frente a Lei 13.709/18 (Lei Geral de Proteção de Dados 
Pessoais (LGPD)), pois há guarida prescrita em relação aos nossos dados, mas serão todos os nossos dados, ou somente em relação a alguns e de toda ordem?

E exatamente neste momento que deixamos ao leitor as considerações acerca dos direitos da personalidade no âmbito do consumidor e o respaldo necessário de nossos dados pessoais perante a lei 13.709/18.

\section{Os direitos da personalidade do consumidor nas relações do e-comerce}

Inicialmente cabe esclarecer o que são de fato os considerados direitos da personalidade, para então haver a necessária compreensão dos direitos da personalidade serem protegidos em relações consumeristas.

De início infere-se que os direitos da personalidade são direitos naturais, inerentes a todo e qualquer ser humano (KANT, 2003, p. 277) estando, por sua vez, relacionado diretamente com a ideia de dignidade humana que, por conseguinte, e tida como um valor supremo da democracia (DA SILVA, 1998, p. 89-94.).

Embora desde a antiguidade já houvesse a preocupação a respeito dos direitos humanos, advinda com o Cristianismo, o reconhecimento dos direitos da personalidade como hoje conhecemos é deveras recente, padecendo por reconhecido pela Declaração dos Direitos do Homem de 1789 e de 1949 firmada nas Nações Unidas, assim como na Convenção Europeia de 1950 (GONÇALVES, 2008, p. 153).

A demais os direitos da personalidade são aqueles que são contemplados pelo direito natural "...dentre outros, o direito à vida, à liberdade, ao nome, ao próprio corpo, à imagem e à honra" (GONÇALVES, 2008, p. 153), são inerentes a todo e qualquer ser humano e, assim, englobam - inclusive -, os consumidores.

Nesta linha aduz-se Paulo Hamilton que os direitos da personalidade (SIQUEIRA JÚNIOR, 2009, p. 28) "surgem dos atributos da pessoa humana, sem os quais ela não pode existir. A personalidade consiste no conjunto de caracteres próprios da pessoa humana... Os direitos da personalidade são afetos à pessoa".

Como visto os direitos da personalidade são afetos à toda e qualquer pessoa humana.

Os direitos inerentes ao ser humano, considerados direitos da personalidade possuem, inclusive, próprio amparo constitucional, quando o texto constitucional pátrio aponta como fundamento do Estado, também, a dignidade da pessoa humana, conforme traz o 
artigo $1^{\text {o }}$, inciso III da Constituição da República Federativa do brasil de 1988 (CRFB/88), que segue:

Art. $1^{\circ}$ A República Federativa do Brasil, formada pela união indissolúvel dos Estados e Municípios e do Distrito Federal, constitui-se em Estado Democrático de Direito e tem como fundamentos:

(...)

III - a dignidade da pessoa humana;

E contempla por dignidade da pessoa humana, direitos intrínsecos ao ser humano, pois são atidos como o piso vital mínimo. Nesse sentido:

\begin{abstract}
O direito à vida privada, à intimidade, à honra, à imagem, dentre outros, aparecem como consequência imediata da consagração da dignidade da pessoa humana como fundamento da República Federativa do Brasil. Esse fundamento afasta a ideia de predomínio das concepções transpessoalistas de Estado e nação, em detrimento da liberdade individual (DE MORAES, 2003, p. 60).
\end{abstract}

No que tange aos direitos da personalidade nas relações de consumo, os direitos aludidos continuam sendo protegidos mesmo que em se tratando de uma relação consumerista, pois são direitos intrínsecos à pessoa e que, portanto, são considerados intransmissíveis e irrenunciáveis, são absolutos, são ilimitados, imprescritíveis, impenhoráveis, não estão sujeitos a desapropriação e, por último - mas não menos importante -, são inalienáveis (GONÇALVES, 2009, p. 156-159) (FLEMING, 2021, p. 01).

$\mathrm{O}$ próprio Código de Defesa do Consumidor abarca princípios inerentes à pessoa humana quando resguarda que mesmo em se tratando de relação consumerista, haverá amparo aos direitos que como verificado são considerados piso vital mínimo, vez que traz em seu bojo política nacional das relações de consumo, mas que vise resguardar direitos intrínsecos à pessoa, conforme podemos depreender do artigo $5^{\circ}$ da Lei $\mathrm{n}^{\circ} 8.078$, de 11 de setembro de 1990(dispõe sobre a proteção do consumidor e dá outras providências).

E nesta toada, inclusive, Eros Grau (1993, p. 03), afirma que;

O Direito, na visão clássica, se prestava unicamente a instrumentar. A partir do momento, no entanto, em que ele amplia a sua atuação e passa a desenvolver políticas, surgem no ordenamento jurídico normas sobre os "fins". É isso que se deflui a nosso ver, do art. $4^{\circ}$. É como se ele dissesse: "há uma política nacional das relações de consumo" e os fins dessa política são aqueles enunciados no próprio art. $4^{\circ}$, ou seja, o art. $4^{\circ}$ é uma norma-objeto, nem norma programática, nem norma de conduta.

De forma bastante clara há mencionado que o próprio CDC trouxe em sua essência a implementação do sistema amparador do consumidor, com viés na proteção dos direitos da 
personalidade o que nesta esteira aduz Toshio (MUKAI apud SODRÉ; MEIRA; CALDEIRA, 2009, p. 36) que;

\begin{abstract}
A implementação de uma Política Nacional de Relações de Consumo, sendo seus objetivos: atendimento das necessidades dos consumidores, respeito à sua dignidade, saúde e segurança, à proteção de seus interesses econômicos, a melhoria de sua qualidade de vida e a transparência e harmonia das relações do consumo.
\end{abstract}

Notadamente verifica-se que o consumidor continua sendo segurado e, assim, encontram-se dispostos os suportes da essência humana à relação consumerista. E ademais, extrai-se dos objetivos deste artigo três blocos, que segundo Marcelo Gomes são eles:

Atendimento das necessidades dos consumidores; respeito à dignidade, saúde, e segurança dos consumidores; harmonia entre consumidores e fornecedores nas relações de consumo, bem como a compatibilização da proteção do consumidor com a necessidade de desenvolvimento econômico e tecnológico (SODRÉ; MEIRA, 2009, p. 41).

O consumidor encontra-se resguardado em seus direitos e garantias fundamentais o que indubitavelmente abarcam os direitos da personalidade, no entanto, com a advinda da sociedade da informação, surgiram inúmeras dúvidas em relação ao amparo necessário ao $e$ commerce.

Com o avançar da tecnologia, a aparelhagem acessível e a internet tomando forma o e-commerce, ainda mais em meio a pandemia da COVID-19 a qual assola de forma impiedosa o mundo, mas que contribui de forma exponencial com o fomento do comércio eletrônico, o mundo se viu em uma situação que não imperava mais a escolha de comprar ou não via online, mas sim todos encontraram-se obrigados a comprar via e-commerce.

Ocorre que muitas vezes a exposição de dados e informações na internet podem gerar grandes problemas de toda ordem, já aduzia Karl Larenz em seu livro em 1980, apontando no mais sobre os efeitos da necessária proteção dos direitos da personalidade, ainda mais contemplados em uma sociedade pós $2^{\circ}$ Guerra Mundial;

A proteção da personalidade humana em seu âmbito próprio, (...) foi em geral avaliada como insuficiente após a Segunda Guerra Mundial. Após a experiência da Ditadura, havia surgido uma sensibilidade diante de toda forma de menosprezo da dignidade humana e da personalidade; ao menos tempo se percebeu que as possibilidade de realizar atos que representem um tal menosprezo, não somente por parte do Estado, mas também por outras associações ou por pessoas privadas, tinham se multiplicado devido ao desenvolvimento da tecnologia (por exemplo, fitas magnéticas, aparelhos de escuta, microcâmaras) (LARENZ, 1980 apud DONEDA, 2019, p. 71). 
Neste mesmo diapasão, alude Armand por base de estudos de Saint-Simon, avençando que a sociedade deve ser tratada como indústria fomentadora, ou seja, há imperiosa necessidade de desenvolvimento no setor tecnológico e informacional através de aliança do governo conjuntamente ao setor de tecnologia e ciência e assim será verificada o progresso esperado seja no âmbito da saúde, da educação, da tecnologia todos atinentes à sociedade da informação, mas que deve ser priorizada a proteção do ser humano juntamente às tecnologias (MATTELART, 2006, p. 31-34) (TERZIDIS; SOUZA, 2021, p. 131) (SOUZA; TERZIDIS; WALDMAN, 2021, p. 40-56).

Afirma ainda Bauman quando cita categoricamente Adorno, que a necessidade de nos debruçarmos sobre fato novo de fato nos faz pensar sobre a questão (ADORNO apud, BAUMAN, 2001, p. 251), para o bom funcionamento da comunidade em que nos enquadramos, verifica-se que os ensinamentos do famoso filósofo não mudam diante do século XXI, pois as preleções continuam sendo imperiosas e necessárias à toda e qualquer elucubração, como à toda e qualquer decisão que possa vir a resvalar à sociedade, implicando na sociedade da informação e no resguardo de informações pessoais que podem desaguar em profunda e desastrosa consequência.

E nesta linha de pensamentos, entende-se que os dados pessoais padecem por uma extensão da personalidade, constituem elementos essenciais de nossa individualidade, e, portanto, são abarcados por reflexos pessoais capazes de nos identificar em nossas particularidades, haja vista sermos seres humanos e sociais e por mesma óptica houve a intenção de apostar a proteção de dados pessoais à categoria de direito da personalidade, que de acordo com a PEC 17/2019 que foi aprovada e que agora há possibilidade de ser incluída nesta categoria (COSTA; DE OLIVEIRA, 2019, p. 11).

A referida Proposta de Emenda à Constituição n. 17 de março de 2019 que foi aprovada 07 do junho de 2021 atualizou o artigo $5^{\circ}$, inciso XII do texto constitucional passando para:

art. $5^{\circ}$ inciso XII - é inviolável o sigilo de correspondência e das comunicações telegráficas de dados e das comunicações telefônicas, salvo, no último caso, por ordem judicial, nas hipóteses e na forma que a lei estabelecer para fins de investigação criminal ou instrução processual penal, bem como é assegurado, nos termos da lei, o direito à proteção dos dados pessoais, inclusive nos meios digitais; 
Bem como poderá ser alterado o artigo 22 que aponta a competência exclusiva da União a fim de legislar, incluindo ao inciso XXX a competência de legislar sobre: "proteção de dados pessoais".

Desta feita, nota-se que com o advento do fomento da internet e seus meios de comunicação e aquisição de bens e serviços vieram de forma paulatina ganhar a frente do mercado, e agora mais do que nunca e com a opção de escolha reduzida necessitamo-nos reportar a inusitada compra on-line ou e-commerce, mas sem, contudo, deixarmos de ter o devido resguardo em relação as informações que aportamos nos sites de compra.

\section{A proteção dos dados pessoais sensíveis do consumidor}

Quando o Brasil adentrou a sociedade da informação o que restou notório pela edição da Lei $\mathrm{n}^{\circ}$ 8.248, de 23 de outubro de 1991, diploma normativo que dispõe sobre a capacitação e competitividade do setor de informática e automação, e dá outras providências, que vigora até os dias de hoje, mas com alterações e atualizações, havia uma série de normas dispostas, mas que em momento algum resguardava a proteção de dados do internauta ou do consumidor de e-commerce.

Com a edição do livro verde de 2000, também havia a mesma questão, o governo à época muito se ateve em diminuir à distância do Brasil com relação aos outros países em desenvolvimento tecnológico do que apostar regulamentação necessária para que os usuários brasileiros da rede mundial de computadores também estivessem abarcados em direitos e preservados em seus dados.

O que também não ficou diferente com a edição do livro branco em 2002, pois a intenção intrínseca da época era a inovação na tecnologia integrada aos países desenvolvidos.

Com o livro azul em 2010 restou a mesma problemática latente, pois aqui nem mais tinha-se o que se falar em inserir o Brasil cada vez mais na sociedade da informação, neste livro havia por motivo diminuir as desigualdades regionais e sociais na exploração de riquezas naturais, mudando o foco às desigualdades, o que foi amplamente discutido à época, pois a edição do livro tratava-se de manutenção do Brasil estar inserido na sociedade informação, mas que, contudo, estivesse resguardo em legislação específica.

Diante da situação imperiosa de se estabelecer princípios, garantias, direitos e deveres para o uso da internet no Brasil que em 2014 no governo da então Presidente Dilma 
Rousseff, foi editada a Lei $\mathrm{n}^{\mathrm{o}}$ 12.965, de 23 de abril de 2014 que veio a estabelecer princípios, garantias, direitos e deveres para o uso da Internet no Brasil, abarcando, assim, a lacuna normativa que havia disposta.

No artigo $3^{\circ}$ da Lei $n^{\circ} 12.965$, de 23 de abril de 2014, de início, há a disposição dos princípios que disciplinarão o uso da internet no Brasil, indicando no mais respeito a proteção dos dados pessoais e proteção à privacidade, dentre outros princípios, conforme aludido abaixo;

\footnotetext{
Art. $3^{\circ}$ A disciplina do uso da internet no Brasil tem os seguintes princípios:

I - garantia da liberdade de expressão, comunicação e manifestação de pensamento, nos termos da Constituição Federal;

II - proteção da privacidade;

III - proteção dos dados pessoais, na forma da lei;

IV - preservação e garantia da neutralidade de rede;

V - preservação da estabilidade, segurança e funcionalidade da rede, por meio de medidas técnicas compatíveis com os padrões internacionais e pelo estímulo ao uso de boas práticas;

VI - responsabilização dos agentes de acordo com suas atividades, nos termos da lei; VII - preservação da natureza participativa da rede;

VIII - liberdade dos modelos de negócios promovidos na internet, desde que não conflitem com os demais princípios estabelecidos nesta Lei.

Parágrafo único. Os princípios expressos nesta Lei não excluem outros previstos no ordenamento jurídico pátrio relacionados à matéria ou nos tratados internacionais em que a República Federativa do Brasil seja parte.
}

Em sequência no artigo $4^{\circ}$ da Lei 12.965 de 2014 traz expresso narrativa referente aos direitos que devem ser resguardos, como é o caso da inviolabilidade da intimidade e da vida privada, a guarda e tratamento de dados pessoais, dentre demais direitos que a legislação alude, mas que precisavam de mais um animo legislativo para serem devidamente aplicada no mundo jurídico.

A proteção ao direito da privacidade, independente da localidade a qual esteja, assim como a proteção dos dados pessoais dos usuários da rede são natos e não podem ser colocados de lado, haja vista que são considerados direitos inerentes do ser humano, segundo aduz Perlingieri (PERLINGIERI, apud DONEDA, 2019, p. 130).

De forma paulatina a vertente da privacidade cada vez mais gira em torno de questões relacionadas a dados pessoais e, portanto, sobre a própria informação (DONEDA, 2019, p. 135).

Importante frisar que diante das práticas abusivas de mercado tradicional e de $e$ commerce houve a necessidade de ser elaborada uma legislação que viesse abarcar a os direitos da personalidade em si mesmo, aduzindo no mais a proteção de dados dos 
consumidores e para tanto, foi editada a Lei 13.709 de 2018 (Lei Geral de Proteção de Dados Pessoais - LGPD), que de início traz no artigo $1^{\circ}$ que a lei irá tratar sobre os dados pessoais nas plataformas digitais, protegendo, contudo, a pessoa natural, bem como a pessoa jurídica de direito privado ou público, conforme segue;

Art. $1^{\circ}$ Esta Lei dispõe sobre o tratamento de dados pessoais, inclusive nos meios digitais, por pessoa natural ou por pessoa jurídica de direito público ou privado, com o objetivo de proteger os direitos fundamentais de liberdade e de privacidade e o livre desenvolvimento da personalidade da pessoa natural.

A própria legislação traz em seu bojo fundamentação muito semelhante a que o próprio marco civil da internet havia trazido quando dispunha dos fundamentos que embasavam a proteção legal, conforme o artigo $2^{\circ}$ da LGPD.

\footnotetext{
Art. $2^{\circ}$ A disciplina da proteção de dados pessoais tem como fundamentos: $\mathrm{I}$ - $\mathrm{o}$ respeito à privacidade;

II - a autodeterminação informativa;

III - a liberdade de expressão, de informação, de comunicação e de opinião;

IV - a inviolabilidade da intimidade, da honra e da imagem;

V - o desenvolvimento econômico e tecnológico e a inovação;

VI - a livre iniciativa, a livre concorrência e a defesa do consumidor; e

VII - os direitos humanos, o livre desenvolvimento da personalidade, a dignidade e o exercício da cidadania pelas pessoas naturais.
}

No entanto, outra questão que há que se frisar são os dados em si, o armazenamento de dados dos consumidores, os bancos de dados, que por sua vez também carecem de guarida legal e proteção quanto ao tratamento dos dados e informações dos consumidores.

Observe que a propriedade da vida privada está sendo paulatinamente cedida à rede. A era do acesso no mundo está transformando dados pessoais em exposição plena e que pode proporcionar grande prejuízo ao titular dos dados.

Sobre o contexto ainda Jeremy (RIFKIN, 2000, p. 2), aponta que a uma valoração sobre a informação o que antes não existia e que demonstra que a informação está paulatinamente ganhando espaço na vida dos indivíduos, pois "na nova era, os mercados estão cedendo lugar às redes, e a noção de propriedade está sendo substituída rapidamente pelo acesso."

Observe como há uma grande exposição em massa atualmente nas redes, a vida privada está hodiernamente estampada na grande vitrine chamada internet.

A destacada preocupação não se perfaz do cotidiano, haja vista que em 1995 o Superior Tribunal de Justiça por meio do Ministro Ruy Rosado de Aguiar (DONEDA, 2019, 
p. 173) já havia se manifestado acerca do imperioso amparo que carece o tratamento de dados pessoais, conforme segue:

\begin{abstract}
A inserção de dados pessoais do cidadão em bancos de informação tem se constituído em uma das preocupações do Estado moderno, onde o uso da informática e a possibilidade de controle unificado das diversas atividades da pessoa nas múltiplas situações de vida, permitem o conhecimento de sua conduta pública e privada, até nos mínimos detalhes, podendo chegar à devassa de atos pessoais, invadindo área que deveria ficar restrita à sua intimidade; ao mesmo tempo, o cidadão objeto dessa indiscriminada colheita de informações, muitas vezes, sequer sabe a existência de tal atividade, ou não dispõem de eficazes meios para conhecer o seu resultado, retificá-lo ou cancelá-lo . E assim com o conjunto dessas informações pode ser usado para fins ilícitos, públicos e privados, na preservação ou repressão de delitos, ou habilitando o particular a celebrar contratos com pleno conhecimento de causa, também pode servir, ao Estado ou ao particular a celebrar contratos com pleno conhecimento de causa, também pode servir, ao Estado ou ao particular, para alcançar fins contrários à moral ou ao Direito, como instrumento de perseguição política ou opressão econômica. A importância do tema cresce de ponto quando se observa o número imenso de ato da vida humana praticados através da mídia ou registrado nos disquetes de computador. (BRASIL. Superior Tribunal de Justiça (4. Turma). Recurso Especial 22.337/RS. Rel. Ministro Ruy Rosado de Aguiar, Quarta Turma, julgado em 13/02/1995, DJ 20/03/1995, p. 03).
\end{abstract}

Em síntese os dados pessoais padecem por uma extensão da personalidade, constituem elementos essenciais de nossa individualidade, e, portanto, são abarcados por reflexos pessoais capazes de nos identificar.

Nesta linha o próprio artigo $5^{\circ}$, inciso I da referida Lei, impõem que dados pessoais são considerados toda aquela informação que verse sobre a pessoa natural identificada ou identificável, que segue;

Art. $5^{\circ}$ Para os fins desta Lei, considera-se:

I - dado pessoal: informação relacionada a pessoa natural identificada ou identificável;

Nesta linha a própria legislação em seu artiogo 38 da Lei 13.709 de 2018 trouxe a existência da categoria de dados denominados sensíveis.

Nesta vertente Danilo (DONEDA, 2019, p. 142) aduz que;

...a prática do direito da informação deu origem à criação de uma categoria de dados, os dados sensíveis. Estes seriam determinados tipos de informação que, caso sejam conhecidas e submetidas a tratamento, podem se prestar a uma potencial utilização discriminatória ou lesiva e que apresenta maiores riscos potenciais do que outros tipos de informação. Entre estes dados, tidos como sensíveis, estariam as informações sobre raça, credo político ou religioso, opção sexuais, histórico médico ou dados genéticos de um indivíduo.

Assim sendo, pode-se deduzir que dados sensíveis tratam-se de dados relacionados as esferas pessoais, extremamente íntimas, que se violadas podem causar graves danos à 
personalidade e à dignidade humana (COSTA; DE OLIVEIRA, 2019, p. 11) (BRASIL, 2021, p. 1), assim como podemos aferir que dados pessoais sensíveis abarcam aqueles associados às opções e características intrínsecas do indivíduo, assim como origem racial ou étnica, convicções religiosas ou filosóficas, opiniões políticas, filiação sindical, questões genéticas, biométricas e sobre a saúde ou a vida sexual de uma pessoa e que podem gerar situações de discriminação e desigualdade, o que inclusive segue especificado pela própria legislação no artigo $5^{\circ}$, inciso II, conforme segue:

\section{Art. $5^{\circ}$ Para os fins desta Lei, considera-se:}

II - dado pessoal sensível: dado pessoal sobre origem racial ou étnica, convicção religiosa, opinião política, filiação a sindicato ou a organização de caráter religioso, filosófico ou político, dado referente à saúde ou à vida sexual, dado genético ou biométrico, quando vinculado a uma pessoa natural;

Ocorre, contudo, que precisa se ter tratamento e proteção efetivada à estes dados, pois o repasse de todo e qualquer passo digital assim como o algoritmo, ou a até mesmo a falta de segurança no controle desses dados, resvala em responsabilidade civil, mas antes mesmo de haver a devida indenização haverá impactos em todos os anglos da vida da pessoa.

Assim sendo, a LGPD trouxe a obrigatoriedade às empresas, que portam consigo dados pessoais e até sensíveis sobre os usuários a cerca do consentimento do titular dos dados no que tange a coleta e armazenamento dos referidos dados pessoais, qual a finalidade da coleta, a utilização (COSTA; DE OLIVEIRA, 2019, p. 13).

No que tange ao consentimento, este deve ser expresso, e sem estar eivado de vícios e determinadas às finalidades de uso de tais dados, conforme alude o artigo $8^{\circ}$ da referida LGPD;

Art. $8^{\circ} \mathrm{O}$ consentimento previsto no inciso I do art. $7^{\circ}$ desta Lei deverá ser fornecido por escrito ou por outro meio que demonstre a manifestação de vontade do titular. $\S 1^{\circ}$ Caso o consentimento seja fornecido por escrito, esse deverá constar de cláusula destacada das demais cláusulas contratuais.

$\S 2^{\circ}$ Cabe ao controlador o ônus da prova de que o consentimento foi obtido em conformidade com o disposto nesta Lei.

$\S 3^{\circ}$ É vedado o tratamento de dados pessoais mediante vício de consentimento. $\S 4^{\circ} \mathrm{O}$ consentimento deverá referir-se a finalidades determinadas, e as autorizações genéricas para o tratamento de dados pessoais serão nulas.

$\S 5^{\circ} \mathrm{O}$ consentimento pode ser revogado a qualquer momento mediante manifestação expressa do titular, por procedimento gratuito e facilitado, ratificados os tratamentos realizados sob amparo do consentimento anteriormente manifestado enquanto não houver requerimento de eliminação, nos termos do inciso VI do caput do art. 18 desta Lei.

$\S 6^{\circ}$ Em caso de alteração de informação referida nos incisos I, II, III ou V do art. $9^{\circ}$ desta Lei, o controlador deverá informar ao titular, com destaque de forma 
específica do teor das alterações, podendo o titular, nos casos em que o seu consentimento é exigido, revogá-lo caso discorde da alteração.

Quanto ao tratamento e proteção de dados pessoais, incluindo os dados sensíveis, a própria LGPD, faz distinção quando aponta que o tratamento de dados referido quando for utilizado pelo trabalho de origem artística, jornalística, ou até mesmo por pessoa natural para fins particulares e não lucrativos não se aplica a proteção distinta, conforme artigo $4^{\circ}$, inciso I e II e alínea "a" da LGPD;

Art. $4^{\circ}$ Esta Lei não se aplica ao tratamento de dados pessoais:

I - realizado por pessoa natural para fins exclusivamente particulares e não econômicos;

II - realizado para fins exclusivamente:

a) jornalístico e artísticos; ou

Para fins de tutela de tratamento pela Lei $\mathrm{n}^{\circ} 13.709$, de 14 de agosto de 2018 (LGPD), somente será cabível quando houver o fornecimento do consentimento expresso pelo titular, quando houver obrigatoriedade legal, pela própria administração pública, para realização de estudos por órgão de pesquisa sendo garantida, se possível, a anonimização dos dados pessoais, quando for necessária execução de contrato sendo qual for o titular, para exercício regular de direito em se tratamento de processo arbitral, para proteção da vida e da saúde e quando for necessário para atender aos interesses legítimos do controlador ou de terceiro e para proteção de crédito, conforme segue abaixo;

Art. $7^{\circ} \mathrm{O}$ tratamento de dados pessoais somente poderá ser realizado nas seguintes hipóteses:

I - mediante o fornecimento de consentimento pelo titular;

II - para o cumprimento de obrigação legal ou regulatória pelo controlador;

III - pela administração pública, para o tratamento e uso compartilhado de dados necessários à execução de políticas públicas previstas em leis e regulamentos ou respaldadas em contratos, convênios ou instrumentos congêneres, observadas as disposições do Capítulo IV desta Lei;

IV - para a realização de estudos por órgão de pesquisa, garantida, sempre que possível, a anonimização dos dados pessoais;

V - quando necessário para a execução de contrato ou de procedimentos preliminares relacionados a contrato do qual seja parte o titular, a pedido do titular dos dados;

VI - para o exercício regular de direitos em processo judicial, administrativo ou arbitral, esse último nos termos da Lei nº 9.307, de 23 de setembro de 1996 (Lei de Arbitragem);

VII - para a proteção da vida ou da incolumidade física do titular ou de terceiro;

VIII - para a tutela da saúde, exclusivamente, em procedimento realizado por profissionais de saúde, serviços de saúde ou autoridade sanitária;

IX - quando necessário para atender aos interesses legítimos do controlador ou de terceiro, exceto no caso de prevalecerem direitos e liberdades fundamentais do titular que exijam a proteção dos dados pessoais; ou

$\mathrm{X}$ - para a proteção do crédito, inclusive quanto ao disposto na legislação pertinente. 
Observe que o tratamento de dados pessoais concernente a base de saúde os usuários do Sistema Único de Saúde (SUS) também estão sujeitos ao risco de vazamento de dados, pois foi lançado um aplicativo denominado E-Saúde em junho de 2016 pelo Ministério da Saúde de âmbito nacional, que - em síntese -, oferece inúmeras informações que possuem direta relação com os titulares de dados como dados do cartão nacional de saúde, lista de medicamentos retirados em unidades de saúde, informações sobre o cartão de vacinação, lista de exames realizados, dentre outros (BARRETO JÚNIOR; FAUSTINO, 2020, p. 306-307).

Observamos que a sociedade conectada revela a importância da regulamentação específica, que contempla as necessidades atuais e as modificações sociais e que com isso acrescente a segurança nas relações de pautadas pelo CDC (COSTA; DE OLIVEIRA, 2019, p. 12). Desta forma, as redes sociais devem se aportar sistemas de segurança dos seus usuários, que consomem seus serviços, produtos, ao cederem seus dados pessoais.

\section{Conclusão}

Infere-se que os direitos da personalidade são direitos os quais encontram-se categoricamente ligados ao ser humano, pois, embora já houvesse a preocupação a respeito dos direitos humanos, advinda com o Cristianismo, o reconhecimento dos direitos da personalidade como hoje conhecemos é deveras recente, reconhecido pela Declaração dos Direitos do Homem de 1789 e de 1949 firmada nas Nações Unidas, assim como na Convenção Europeia de 1950.

Os direitos da personalidade englobam aqueles direitos fundamentais, assim pela base do princípio da dignidade, também previstos no texto constitucional que são contemplados no próprio Código Civil e dentre outros, são considerados o direito à vida, à liberdade, ao nome, ao próprio corpo, à imagem e à honra.

O próprio Código de Defesa do Consumidor abarca princípios inerentes à pessoa humana quando resguarda que mesmo em se tratando de relação consumerista, haverá amparo aos direitos que como verificado são considerados piso vital mínimo, vez que traz em seu bojo política nacional das relações de consumo, mas que vise resguardar direitos intrínsecos à pessoa, conforme podemos depreender do artigo $5^{\circ}$ da Lei $\mathrm{n}^{\circ} 8.078$, de 11 de setembro de 1990 que dispõe sobre a proteção do consumidor e dá outras providências). 
Notadamente verifica-se que o consumidor continua sendo resguardado em seus direitos e garantias fundamentais o que indubitavelmente abarcam os direitos da personalidade, no entanto, com a advinda da sociedade da informação, surgiram inúmeras dúvidas em relação ao amparo necessário em se tratando de plataforma digital.

Diante da situação imperiosa de se estabelecer princípios, garantias, direitos e deveres para o uso da internet no Brasil que em 2014 no governo da então Presidente Dilma Rousseff, foi editada a Lei $\mathrm{n}^{\mathrm{o}}$ 12.965, de 23 de abril de 2014 que estabeleceu princípios, garantias, direitos e deveres para o uso da Internet no Brasil, abarcando, assim, a lacuna normativa.

Nesta lei havia previsão dos respaldos e direitos intrínsecos dos internautas enquanto pessoa humana, mas faltava a efetividade, então em 2018, foi editada a Lei $\mathrm{n}^{\circ} 13.709$, de 14 de agosto de 2018 (Lei Geral de Proteção de Dados Pessoais - LGPD), que de início traz no artigo $1^{\circ}$ que a lei irá tratar sobre os dados pessoais nas plataformas digitais, protegendo, contudo, a pessoa natural, bem como a pessoa jurídica de direito privado ou público.

No entanto, outra questão que há que se frisar são os dados em si, o armazenamento de dados dos consumidores, o que sempre padeceu por lacunosa em outras legislações, nesta o legislador conseguiu abordar, inclusive esclarecendo acerca de bancos de dados, que por sua vez também carecem de guarida legal e proteção aos consumidores.

Apontando em síntese os dados pessoais padecem por uma extensão da personalidade, constituem elementos essenciais de nossa individualidade, e, portanto, são abarcados por reflexos pessoais capazes de nos identificar em nossas particularidades, haja vista sermos seres humano e sociais, e por mesma óptica há intenção de apostar a proteção de dados pessoais à categoria de direito da personalidade, que de acordo com a PEC 17/2019 há possibilidade de ser inclusiva nesta categoria.

Já outra categoria que deve ser reverenciada são dos dados pessoais sensíveis, os quais tratam-se de dados relacionados as esferas pessoais, extremamente íntimas, que se violadas podem causar graves danos à personalidade e à dignidade humana, assim como podemos aferir que dados pessoais sensíveis abarcam aqueles associados às opções e características intrínsecas do indivíduo, assim como origem racial ou étnica, convicções religiosas ou filosóficas, opiniões políticas, filiação sindical, questões genéticas, biométricas e sobre a saúde ou a vida sexual de uma pessoa e que podem gerar situações de discriminação e desigualdade. 
A título de tratar de tais dados dos consumidores e de todo os usuários a Lei Geral de Proteção de Dados Pessoais - LGPD -, apostou em tratamento e proteção adequados, assim as plataformas precisam do consentimento expresso pelo titular, quando houver obrigatoriedade legal, pela própria administração pública, para realização de estudos por órgão de pesquisa sendo garantida, se possível, a anonimização dos dados pessoais, quando for necessária execução de contrato sendo qual for o titular, para exercício regular de direito em se tratamento de processo arbitral, para proteção da vida e da saúde e quando for necessário para atender aos interesses legítimos do controlador ou de terceiro e para proteção de crédito.

No entanto, ainda há grande preocupação derivada de meados de 1995 o qual o Ministro do STJ à época havia reportado sobre a imensidão de informações frente a demasiada exposição de dados de consumidores em bancos de dados e plataformas digitais que podem, uma vez vasados, acarretar prejuízos de diversas vertentes, há então de se ter efetividade nesta legislação que agora sana inúmeras lacunas normativas que antes eram atidas por outras legislações.

Assim padece de início a necessidade de as políticas públicas serem aplicadas, a fim de evitar atos irresponsáveis por parte de plataformas que não obstante, diuturnamente padecem por ceder dados de usuários dentre outras práticas condenáveis e que podem acarretar grande prejuízo aos titulares de dados e informações pessoais. 


\section{Referências}

BARRETO JUNIOR, Irineu Francisco; FAUSTINO, André. Aplicativos de serviços de saúde e proteção dos dados pessoais dos usuários. Revista Jurídica. Vol. 01, n . 54, Curitiba, 2019. p. 292 - 316. DOI: 10.6084/m9.figshare.7841105. Disponível em:

<http://revista.unicuritiba.edu.br/index.php/RevJur/article/view/3311/371371803>. Acesso em 28 nov. 2021.

BAUMAN, Zygmunt. Modernidade Líquida. Editora Zahar: Rio de Janeiro, 2001.

BRASIL. Constituição da República Federativa do Brasil de 1988. Disponível em: http://www.planalto.gov.br/ccivil_03/constituicao/constituicao.htm. Acesso em: 26 de nov. de 2021.

BRASIL. Lei $\mathbf{n}^{\mathbf{0}}$ 12.965, de 23 de abril de 2014. Estabelece princípios, garantias, direitos e deveres para o uso da Internet no Brasil. Disponível em:

http://www.planalto.gov.br/ccivil_03/_ato2011-2014/2014/lei/112965.htm. Acesso em: 10 set. 2021.

BRASIL. Lei No 13.709, de 14 de agosto de 2018. Lei Geral de Proteção de Dados Pessoais (LGPD). Disponível em: http://www.planalto.gov.br/ccivil_03/_ato2015-

2018/2018/lei/113709.htm. Acesso em: 10 set. 2021.

BRASIL. Lei no 8.078, de 11 de setembro de 1990. Dispõe sobre a proteção do consumidor e dá outras providências. Disponível em:

http://www.planalto.gov.br/ccivil_03/leis/18078compilado.htm. Acesso em: 10 set. 2021.

BRASIL. Lei $\mathbf{n}^{\circ}$ 8.248, de 23 de outubro de 1991. Dispõe sobre a capacitação e competitividade do setor de informática e automação, e dá outras providências. Disponível em: http://www.planalto.gov.br/ccivil_03/leis/18248.htm. Acesso em: 10 set. 2021.

BRASIL. Serpro e LGPD: segurança e inovação. O que são dados sensíveis, de acordo com a LGPD. Disponível em: https://www.serpro.gov.br/lgpd/menu/protecao-de-dados/dadossensiveis-lgpd. Acesso em: 10 set. 2021.

BRASIL. Superior Tribunal de Justiça (4. Turma). Recurso Especial 22.337/RS. Serviço de proteção ao crédito. cancelamento do registro. prazo (cinco anos). o registro de dados no SPC deve ser cancelado após cinco anos. art. 43, parágrafo 1, do código de defesa do consumidor (lei 8.078/90). Recorrido: José Orivaldo Moreira Branco. Relatora: Min. Ruy Rosado de Aguiar, 20 de março de 1995. Disponível em:

https://scon.stj.jus.br/SCON/GetInteiroTeorDoAcordao?num_registro=199200114466\&dt_pu blicacao=20/03/1995. Acesso em: 28 nov. 2021.

COSTA, Ramon Silva. DE OLIVEIRA, Samuel Rodrigues. Os direitos da personalidade frente à sociedade de vigilância: privacidade, proteção de dados pessoais e consentimento nas redes sociais. Revista Brasileira de Direito Civil em Perspectiva, 2019. 
DA SILVA, José Afonso. A dignidade da pessoa humana com valor supremo da democracia. Revista de direito administrativo, v. 212, p. 89-94, 1998.

DE MORAES, Alexandre. Direitos humanos fundamentais. 5. ed. São Paulo: Atlas, 2003.

DONEDA, Danilo. Da privacidade à proteção de dados pessoais. 2. ed. São Paulo: Revista dos Tribunais, 2019.

FLEMING, Maria Cristina. OPINIÃO LGPD: diferenças no tratamento de dados pessoais e dados pessoais sensíveis. Disponível em: https://www.conjur.com.br/2021-mar-06/flemingdiferencas-tratamento-dados-pessoais-sensiveis. Acesso em: 10 set. 2021.

GONÇALVES, Carlos Roberto. Direito Civil Brasileiro. Volume I. 6. ed. São Paulo: Saraiva, 2008.

GRAU, Eros Roberto. Interpretando o Código de Defesa do Consumidor algumas notas. Direito do Consumidor. São Paulo Revista dos Tribunais online, n. 5, 1993.

KANT, Immanuel. A metafísica dos costumes. Tradução Edson Bini. São Paulo: Edipro, 2008.

RIFKIN, Jeremy. A Era do Acesso. São Paulo: ed. Pearson, 2000.

SIQUEIRA JÚNIOR, Paulo Hamilton. DE OLIVEIRA, Miguel Augusto Machado. Direitos Humanos e Cidadania. 2. Ed. São Paulo: Revista dos Tribunais, 2009.

SODRÉ, Marcelo Gomes. MEIRA, Fabiola. Comentários do Código de Defesa do Consumidor. São Paulo: Editora Verbatim, 2009.

SOUZA, Devanildo de Amorim; TERZIDIS, Cristina Anita Schumann Lereno; WALDMAN, Ricardo Libel. O aprimoramento da tecnologia e seu potencial de fomentar avanços e retrocessos sociais na sociedade da informação. Revista de Direito, Governança e Novas Tecnologias, v. 7, 2021. p. 40-56. Disponível em:

https://indexlaw.org/index.php/revistadgnt/article/view/7862. Acesso em 28 set. 2021.

TERZIDIS, Cristina Anita Schumann Lereno; SOUZA, Devanildo de Amorim. Da sociedade da informação: do comércio tradicional ao e- comerce e à relação consumerista. In: III ENCONTRO VIRTUAL DO CONPEDI. Anais Direito, Globalização e Responsabilidade nas Relações de Consumo. Santa Catarina: CONPEDI, 2021. p. 118-134. Disponível em: http://site.conpedi.org.br/publicacoes/276gsltp/7hv0e719/Mcovq607RMMKhz8m.pdf. Acesso em 28 nov. 2021. 